\title{
Promoting plurilingual and pluricultural competence in language learning through Audiovisual Translation
}

Rocío Baños, Anna Marzà and Gloria Torralba

University College London / Universitat Jaume I / Universitat Jaume I

The effectiveness of audiovisual translation (AVT) for language learning has been widely discussed and demonstrated by scholars in the past (cf. Lertola 2019). Nevertheless, many areas in this field of investigation are still underexplored, such as the usefulness of AVT for the acquisition of plurilingual and pluricultural competence (PPC). This is of paramount importance in the multilingual and multicultural societies we live in, and also given the emphasis the CEFR Companion Volume (Council of Europe 2018) places on mediation and PPC. The latter has been the focus of the research project PluriTAV (2017-2019), in which the authors of this paper have taken part, aimed at developing a set of activities involving the use of AVT for the acquisition of PPC in the language classroom. This paper sets out to illustrate the theoretical framework sustaining the PluriTAV project and to reflect on the potential of AVT for the acquisition of PPC. This will be achieved by establishing links between AVT modes, transfer/mediation skills, and the descriptors developed within the Framework of Reference for Pluralistic Approaches to Languages and Cultures (FREPA) (Candelier et al. 2012), as well as referring to sample and specific activities developed within PluriTAV. In line with this project, the emphasis will be on language teaching in Higher Education, yet the discussion and the activities suggested could be easily extrapolated and adapted to other educational contexts and levels of language ability. 
Keywords: plurilingual and pluricultural competence (PPC), audiovisual translation, language learning, pedagogical translation, Framework of Reference for Pluralistic Approaches to Languages and Cultures (FREPA), mediation skills, transfer skills, PluriTAV

\section{Introduction}

In audiovisual texts, multiple codes (i.e. sounds, images, paralanguage, etc.) interact to convey meaning and, as a result, their translation includes both linguistic and semiotic transfer (Chaume 2012). The different types or modes of Audiovisual Translation (AVT) comprise all three types of translation defined by Jakobson (1959): intralingual, related to the signs of one language only; interlingual, which occurs between two different languages; and intersemiotic, which involves a translation between two different media. For instance, dubbing and subtitling are clear examples of interlingual translation, where dialogue and onscreen text are translated from one language into another; subtitling for d/Deaf and hard of hearing viewers must reformulate the aural messages to written messages in the same language (intralingual translation) while verbalising sounds and relevant voice inflections (intersemiotic translation); and audiodescription for blind and visually impaired people deals with the transfer between two different media—visual to verbal—, thus representing a different type of intersemiotic translation.

The multimodality of audiovisual texts and the variety of AVT types available can be especially useful in language learning. AVT is particularly suited to address a wide range of mediation activities and strategies presented in the Common European Framework of Reference (CEFR) (Council of Europe 2001) and its Companion Volume (Council of Europe 2018), such as processing text, reformulating, adapting language, etc. Although the usefulness of AVT in language learning has been proven in recent studies (cf. Lertola 2019 for an up-to-date overview of studies involving a wide range of AVT types), which have 
shown how AVT activities (e.g. subtitling a short clip from one language into the language being taught) can be effectively integrated in the language classroom (see section 3 below), its use in the development of plurilingual and pluricultural competence (PPC) is still underexplored. The project PluriTAV was precisely designed to address this gap, inspired by previous research and taking into consideration the emphasis the CEFR and the Companion Volume place on mediation skills and PPC (Council of Europe 2001, 2018). Funded by the Spanish Government and the European Regional Development Fund (ERDF) from 2017 to 2019, the project involved the participation of two universities in Spain (Universitat de València and Universitat Jaume I) and in the UK (University College London and University of Roehampton). Its conceptualisation was guided by three principles: firstly, the notion of language learning as a process, based primarily on language use, and as a reflective practice, where learners analyse and create texts in contextualised and meaningful situations (Fons Esteve 1999); secondly, the idea that language teaching in a multilingual environment needs to embrace and foster the students' plurilingualism and the particular skills that it entails (Guasch 2007); and finally, the use of active AVT (cf. Talaván 2010; Incalcaterra McLoughlin, Lertola, and Talaván 2018) to enhance linguistic and plurilingual skills. As regards the latter, Incalcaterra McLoughlin, Lertola and Talaván $(2018,2)$ consider this application of AVT, "in which learners are involved in the audiovisual translation process itself," to be a methodological and operational approach which "exploits a combination of receptive and productive tasks, facilitating meaningful interaction in the target language." PluriTAV's aim was, then, to conceptualise, plan and test teaching tools that incorporated and exploited the above-mentioned three tenets.

Didactic Sequences (Dolz-Mestre and Schneuwly 1998) were used as a tool to provide a meaningful context and prioritise the use of real texts and genres in PluriTAV. A Didactic Sequence (DS) is a linguistic project in which students aim to produce an oral, 
written or multimodal text that belongs to a specific genre, with a specified communicative aim. Each DS is formed by several workshops that tackle the skills, knowledge, and attitudes that students will need to produce the final text. Within PluriTAV, DSs are organised according to the main AVT mode used (specifically dubbing, subtitling, audio description and free commentary) and AVT activities are implemented in different ways. For instance, while in some DSs the final product involves the translation of an audiovisual text, in others small-scale AVT activities are integrated throughout the workshops. PluriTAV's quasi-experimental phase, which involved testing the DSs created with control and experimental groups (see Martínez Sierra, forthcoming), was developed in a multilingual context at Higher Education, where students had either Spanish or Catalan as L1 and L2, and were learning English as an Additional Language (AL), ${ }^{1}$ with various levels of language ability, ranging from $\mathrm{B} 2$ to $\mathrm{C} 1$.

Against this backdrop, the plurilingual approach lies at the very core of the project, and was incorporated to the planning of DSs by linking plurilingual descriptors (Candelier et al. 2012) to competences related to mediation (i.e. transfer/mediation skills) that can be addressed through AVT (see section 2.2 below). The theoretical reasoning that led to such conceptualisation will be detailed in the following section. The aim is ultimately to provide researchers and practitioners with a sound framework for the use of AVT in the language classroom with an emphasis on PPC and transfer/mediation skills, thus complementing the existing theoretical and methodological proposals that focus on the teaching of other CEFR language activities.

\section{Theoretical framework}

As will be discussed below, PluriTAV's theoretical framework draws largely on plurilingual approaches in language learning and on the potential of AVT in the development of PPC. This 
framework has supported the creation of five DSs (available from

http://citrans.uv.es/pluritav/sd/?lang=en) and their testing at a later stage. These are not discussed here due to space constraints, but the reader can find further information on the detailed implementation of PluriTAV's methodological and theoretical framework in Martínez Sierra (forthcoming).

\subsection{Plurilingual approaches in language learning}

Since the publication of the CEFR (Council of Europe 2001), the concept of plurilingual and pluricultural competence has slowly but steadily grown inextricably linked to the act of teaching and learning languages. The notion that all linguistic abilities interact, as previously stated by Cummins' (1979) seminal work, and conform a single but complex competence on which the user may draw, completely modifies the aim of language education, where the knowledge of specific languages is now regarded as a pathway to develop a linguistic repertory (Council of Europe 2001).

Within this paradigm, research in language acquisition has undergone an important shift towards a more complex, holistic understanding of linguistic processes in plurilinguals (Herdina and Jessner 2002). Different yet complementary theoretical frameworks explore the complexities of language use and language learning in plurilinguals, such as the “didactics of plurilingualism" (Nussbaum 2014), the "focus on multilingualism" (Cenoz and Gorter 2014), or "translanguaging" (García and Seltzer 2016), to cite just a few. A particular concern within this field is the development of practical pedagogical approaches to language learning that embrace the notion of plurilingual and pluricultural competence and make it the focus of education. Candelier et al. $(2012,6)$ have labelled these educational approaches as "pluralistic", and have defined them as "didactic approaches which use 
teaching/learning activities involving several (i.e. more than one) varieties of languages or cultures.”

The distinction between theoretical approaches and didactic practices is not clear-cut in all cases. However, the existing literature describes specific practices that contribute to students' PPC, such as “awakening to languages" (Armand et al. 2004), the "intercomprehension of related languages" (Pinho and Andrade 2009), "integrated language learning” (Hufeisen and Neuner 2004), “a translanguaging pedagogy” (Celic and Seltzer 2012), or the use of translation as a pedagogical approach (Cummins 2007; de Pietro 2014). All these didactic approaches foreground this field's richness and highlight a clear interest to conceptualise, develop, and test tools to enhance PPC, which is the objective of PluriTAV. In fact, translation lies at the core of plurilingual and pluricultural competence as conceived by the CEFR, which takes the definition from Coste et al. ([1997] 2009). According to these authors, the new concept of plurilingual and pluricultural competence involved important paradigmatic shifts that broadened the vision of languages, including a focus in "circulations, mediations and passages between languages and between cultures" (Coste et al. [1997] 2009, v). The CEFR incorporated this idea with the inclusion of mediation as one of the four central language activities: reception, production, interaction and mediation, in particular interpreting or translating (Council of Europe 2001, 14, 87). In spite of this advance, the CEFR established levels of competency linked to languages as separate entities and did not include specific descriptors to operationalise the notion of plurilingual and pluricultural education, thus making it harder for educational practitioners, researchers and curriculum developers to pin down and apply the concept. To bridge this gap, the Council of Europe supported the elaboration of a framework that defined knowledge, skills and attitudes which could be developed by using pluralistic or multilingual approaches to language teaching and learning, the Framework of Reference for 
Pluralistic Approaches to Languages and Cultures (FREPA) (Candelier et al. 2012). In 2018, the Companion Volume to the initial CEFR was published, with specific descriptors for the language activities of mediation (Council of Europe 2018). Although this last publication has reached a wider audience, the initial stages of PluriTAV took place before the Companion was available and, among the existing literature, the exhaustivity of FREPA in describing PPC was deemed most appropriate for the conceptualisation of PluriTAV's framework. As a result, the theoretical framework of this article does not refer to the 2018 Companion Volume. However, references to this volume have been included whenever relevant in section 3, in the presentation of sample AVT activities.

2.2 Audiovisual translation, language learning and plurilingual/pluricultural competence

While attitudes towards the use of translation in the language classroom have shifted substantially over time (Carreres 2014; Carreres, Noriega-Sánchez, and Calduch 2018; Pintado Gutiérrez 2019), nowadays there seems to be a consensus regarding the key role that translation plays in the teaching and learning of languages in a wide range of contexts (see section 3). Given the renewed interest witnessed in this area, as well as the surge of research activity in this field, Carreres, Noriega-Sánchez and Calduch (2018, viii) argue that we seem to be entering a "translation turn in language pedagogy." As the authors contend, this turn involves considering translation both as a means (i.e. as a helpful tool to improve linguistic competence), and as an end (i.e. as a key skill for any language learner and not only for trainee translators).

The role of translation as an end falls within the remit of translation training and is thus closely related to the notion of translation competence, understood as "the underlying system of knowledge, skills and attitudes needed to translate" (PACTE group 2017, 294). 
Translation competence is therefore made up of a set of sub-competences activated in every act of translation (ibid.), and while the classifications of sub-competences suggested by translation scholars vary (cf. González-Davies 2004; Kelly 2005; PACTE group 2017), the underlying principles are very similar.

Within PluriTAV, our focus was on AVT sub-competences and how they intertwine with PPC. In order to investigate this relationship further, the classification proposed by Cerezo-Merchán (2018) was analysed with a view to mapping AVT sub-competences to FREPA descriptors. While there is clear overlapping between the list of sub-competencies provided by Cerezo-Merchán and the plurilingual/pluricultural skills to be expected from language learners, ${ }^{2}$ the classification would require significant adjustment to be useful in a language learning context. In our particular setting, however, the notion of "Translation for Other Learning Contexts (TOLC)” (González-Davies 2017, 2020) was deemed more appropriate.

González-Davies $(2017,129)$ defines TOLC as translation used "to acquire linguistic mediation skills and intercultural competence in fields other than translation studies," thus distinguishing it from translation used to acquire professional translator competence. This notion is essential in the Integrated Plurilingual Approach (IPA) she advocates, where translation is implemented following socio-constructivist pedagogical practices to advance not only language learning, but also plurilingual and intercultural communicative competence. Within the PluriTAV project, the concept of TOLC seemed particularly suited to the investigation of PPC, as it provides students with opportunities to work on "communicative interlinguistic and intercultural production, reception, mediation and interaction", thus becoming "a key translanguaging scaffolding activity to develop plurilingual competence" (González-Davies 2020, 445). 
The focus was therefore placed on how translation competence can be perceived within TOLC, that is, as "a set of specific linguistic, encyclopaedic and transferential skills, along with specific intra- and interpersonal skills that may enhance language learning” (González-Davies 2014, 15). Regarding these skills, in a previous publication, GonzálezDavies (2004) refers to the following three macro-competences:

- Linguistic knowledge. It refers to the level of language competence and performance. In addition to knowledge of the source and target languages, it also involves an awareness of potential interference and negative transfer between them.

- Encyclopaedic knowledge. This includes recognising the cultural references and intertextuality embedded in a text, as well as being aware of the importance of familiarity with the subject dealt with in the text.

- Transference skills. These are the mental operations needed both to optimise the relation established between linguistic and encyclopaedic knowledge, and to transfer the source text for a target audience appropriately.

While González-Davies $(2020,446)$ contends that these competences can be expected from both language learners and translation students, she also explains that transfer skills are at the basis of translation competence. Nevertheless, she does not develop these skills further within a TOLC context and/or for the implementation of the Integrated Plurilingual Approach, making it necessary to go beyond these transfer skills and establish further links with existing frameworks. In this regard, clear connections can be identified between these transfer skills and the mediation strategies included in the CEFR, implemented in oral and written mediation, i.e. when "the language user is not concerned to express his/her own meanings, but simply to act as an intermediary between interlocutors who are unable to understand each other directly" (Council of Europe 2001, 87). These mediation strategies may involve: planning to organise resources to process information and establish equivalent 
meaning in mediation activities; previewing, bridging gaps and making decisions during the mediation process; evaluating the results of the mediation activity, checking both consistency and congruence; and reviewing/repairing after consulting specific resources (ibid, 87-88).

Given the shortcomings yet complementarity of existing proposals, it was decided to concentrate on transfer/mediation skills in our theoretical framework, always with the aim of designing a manageable and useful method that would clearly illustrate the links between translation competence/mediation strategies/transfer skills in AVT and PPC.

\subsubsection{Mapping transfer/mediation skills and plurilingual/pluricultural descriptors}

FREPA (Candelier et al. 2012) provides a very sophisticated and complex framework organised around competences and descriptors. The latter are classified into three further categories: Knowledge, Skills and Attitudes. While all these resources or descriptors are relevant, in PluriTAV the emphasis was placed on the former two, given the focus of the project and the need to have measurable objects (i.e. the attainment of Attitudes was more difficult to quantify within a short period of time, as was our case). In addition, since the list of descriptors pertaining to the categories of Knowledge and Skills is extremely detailed, it was considered appropriate to narrow it down to focus only on those descriptors that could be clearly addressed and developed through translation in general, and through AVT in particular. To this end, the selection process was guided by the following question: Which descriptors are directly related to transfer/mediation skills within a TOLC context?

As a result of the selection process undertaken, our framework relies on three different descriptors for each of the two categories chosen (see Table 1). These descriptors have several subdescriptors which have not been included in Table 1 due to space constraints, yet are available from Candelier et al. (2012). 
Table 1. Selection of FREPA descriptors for PluriTAV framework

\begin{tabular}{|c|c|c|}
\hline \multirow{3}{*}{ KNOWLEDGE } & $\mathbf{K 3}$ & $\begin{array}{l}\text { Knows some of the principles of how [verbal and non-verbal] } \\
\text { communication functions }\end{array}$ \\
\hline & K6 & $\begin{array}{l}\text { Knows that there are similarities and differences between } \\
\text { languages and linguistic variations }\end{array}$ \\
\hline & K13 & $\begin{array}{l}\text { Knows that resemblances and differences exist between } \\
\text { (sub)cultures }\end{array}$ \\
\hline \multirow{3}{*}{ SKILLS } & S3 & $\begin{array}{l}\text { Can compare linguistic or cultural features of different } \\
\text { languages or cultures (or, can perceive or establish linguistic or } \\
\text { cultural proximity and distance) }\end{array}$ \\
\hline & S5 & $\begin{array}{l}\text { Can use knowledge and skills already mastered in one language } \\
\text { in activities of comprehension or production in another } \\
\text { language }\end{array}$ \\
\hline & S6 & $\begin{array}{l}\text { Can interact in situations of contact between languages or } \\
\text { cultures }\end{array}$ \\
\hline
\end{tabular}

The descriptors selected within the Knowledge category refer to knowledge of how communication works, as well as of similarities and differences between languages and cultures, all of which are essential in mediation and translation tasks. The link between these descriptors and translation—especially as regards skills which go beyond the declarative knowledge of two or more languages and cultures, and require "a good command of transference or bridging skills" (González-Davies 2004, 167)—is obvious if we pay attention to descriptors such as K6.2.2 "Knows therefore that in translating from one language to 
another there is rarely a word for word solution, a simple exchange of labels, but that one should see the process within the context of a different perception or organisation of reality."

While it could be argued that the descriptors above could be developed with any kind of translation-related activity, we believe that the implementation of AVT activities would allow addressing several of them at the same time. In addition, the rich linguistic and cultural information portrayed simultaneously through the visual and the acoustic channel in audiovisual material allows language teachers to work with verbal and non-verbal forms of communication in an engaging manner. In this regard, AVT modes aimed at making audiovisual content accessible (i.e subtitles for $\mathrm{d} /$ Deaf and hard-of-hearing viewers or audio description) can be used in the language classroom to reflect on the amount of non-verbal information that is included in an audiovisual text, how it may be inaccessible to some viewers, and how this can be resolved through intersemiotic and intralingual transfer. Likewise, the profusion of genres and registers portrayed in audiovisual material provides language teachers with excellent opportunities to work with a wide variety of languages (e.g. through multilingual films) and linguistic variations (see descriptor K6), and to expose students to sociocultural and pragmatic elements belonging to different (sub)cultures (see descriptor K13). As will be illustrated in the following section, when translating audiovisual content students will need to take into consideration aspects such as space and time constraints or synchronisation between text and image, thus addressing specific forms of mediation (see descriptors K6.10 and K3.4 in Candelier et al. 2012) while making mediation and translation activities more challenging and engaging.

Similarly, the descriptors selected within the Skills category refer to activities of comprehension, production, interaction, and mediation between languages or cultures. These descriptors refer to the ability to carry out both interlingual (see S5.3) and intralingual transfers (S5.4), thus revealing the interconnection with transfer skills and the ability to 
implement translation strategies successfully. Audiovisual material can be used in a very creative manner in the language classroom so that students engage with intralingual transfers, i.e. by asking them to create subtitles in the S/AL for a video with dialogues also in the S/AL, or to record such dialogues with their own voices to practice oral skills (i.e. intralingual dubbing).

The discussion has so far illustrated that the selection of FREPA descriptors for the PluriTAV framework has taken several parameters into consideration, being guided by both the needs of the project and the desire to achieve a manageable tool to design activities and didactic sequences involving the use of AVT in the language classroom. The following section will illustrate the connections established throughout PluriTAV between PPC, transfer/mediation skills and AVT with specific examples.

\section{AVT modes, transfer/mediation skills and plurilingual/pluricultural competence}

This section will be articulated around specific AVT modes; however, due to space constraints the focus will be on the most widespread ones: subtitling and dubbing. Each of those AVT modes will be briefly defined and contextualised as regards S/AL learning research. The discussion will then illustrate some of the FREPA descriptors that could be addressed through the AVT mode being analysed, establishing links with the CEFR Companion Volume's mediation skills or activities whenever possible. Far from being exhaustive or exclusive to a specific AVT mode, the aim of this list is to illustrate the potential connections that can be made between AVT modes, descriptors and transfer/mediation skills. To transition from theorisation to application, and to help readers understand how a specific AVT mode could be used for the implementation of pluralistic approaches to language teaching and learning, two sample activities that language teachers 
could adapt to their own context will be briefly presented. Finally, examples of how these types of activities have been implemented in PluriTAV DSs will be provided.

\subsection{Subtitling}

Díaz-Cintas and Remael $(2007,8)$ define subtitling as "a translation practice that consists of presenting a written text $[\ldots]$ that endeavours to recount the original dialogue of the speakers, as well as the discursive elements that appear in the image [...], and the information that is contained on the soundtrack." Although these can vary depending on the context, subtitling involves complying with specific spatio-temporal parameters and bearing in mind concrete linguistic aspects such as text reduction.

Subtitling has been the first and most widely investigated AVT mode in S/AL learning research, with a number of studies highlighting and/or demonstrating the benefits of both consuming subtitled audiovisual programs (among others, Vanderplank 1988; Danan 1992; Caimi 2006), and producing subtitles (among others, Díaz-Cintas 1995; Williams and Thorne 2000; Talaván 2006). Regardless of whether subtitling is used as an active or passive tool, research has highlighted its benefits as regards oral comprehension (Caimi 2006) and, especially, lexical improvement, including vocabulary acquisition, language expression, and writing skills (Lertola 2012; Talaván et al. 2017).

The advantages of subtitling for the acquisition of PPC are underexplored, but the links that can be established between this AVT mode and FREPA descriptors and transfer/mediation skills are evident. For instance, due to the need to comply with spatiotemporal constraints, subtitling involves condensing and reformulating, and therefore working on descriptor K3.4 "Knows that there exists language means to facilitate communication (e.g. simplification, reformulation, etc.)." In addition, the need to preserve syntactic units in the 
same line as well as maintaining legibility is fully represented in some descriptors, such as those dealing with the construction or organisation of utterances (i.e. K6.8 "Knows that the organisation of an utterance may vary from one language to another").

\subsubsection{Sample activity 1. Translating and condensing verbatim subtitles}

- Material needed: Clip and script in S/AL divided into verbatim subtitles

- Aims:

- Translate the text complying with space restrictions

- Identify key words and main ideas

- Apply paraphrasing/reformulating strategies

- Mediation skills and FREPA descriptors targeted: See Table 2 below

- Example of this type of sample activity within a PluriTAV DS:

http://citrans.uv.es/pluritav/sd/resources/sd/SD_SUBTITLING.pdf (Session 4, activity B4)

Table 2. Mediation skills and FREPA descriptors related to the translation and condensation of verbatim subtitles

\begin{tabular}{|l|l|}
\hline $\begin{array}{l}\text { Mediation skills } \\
\text { (Adapted from CEFR Companion Volume 2018, } \\
\text { 108-129) }\end{array}$ & FREPA descriptors \\
\hline $\begin{array}{l}\text { Translating with the aim of conveying } \\
\text { essential information }\end{array}$ & K6.6 Knows that there is no word for \\
& word equivalence from one language to \\
& Konother \\
\cline { 2 - 2 } & K6.8 Knows that the organisation of an \\
& another \\
\hline
\end{tabular}




\begin{tabular}{|l|l|}
\hline & $\begin{array}{l}\text { S6.4 Can communicate "between } \\
\text { languages" }\end{array}$ \\
\hline Summarising main points in a source text & K3.4 Knows that there exists language \\
Streamlining a text excluding what is not & simplification, reformulation, etc.) \\
\cline { 2 - 2 } relevant for the audience to comply with & S5.4 Can carry out intralingual transfers \\
space restrictions & (preceding or following interlingual \\
Adapting language, paraphrasing & transfers) \\
\hline
\end{tabular}

In this type of activity students are given verbatim subtitles to be translated, as well as the original clip, which in line with PluriTAV's approach based on DSs should ideally (in all cases and sample activities) be a short text that constitutes a genre in itself, such as microshort films or advertisements. As with any interlingual translation activity, the translation of subtitles involves showing an ability to communicate between languages (descriptor S6.4), taking into consideration the lack of literal or direct equivalence between them (descriptor K6.6), and reorganising utterances as necessary (descriptor K6.8). In this kind of activity, further reorganisation might be required given the need to comply with specific spatiotemporal constraints (see below) and to make sure that subtitles can be easily read while they appear on screen, thus highlighting the advantages of using subtitling activities (vs. more traditional translation tasks) to address these descriptors. Since dialogues need to appear on screen for a limited amount of time, restricting the amount of characters/words viewers can read (i.e. subtitles nowadays have a maximum of two lines, and each line rarely exceeds 41 characters), condensation and reformulation are also required. This allows students to work on descriptors such as K3.4 and S5.4. As far as descriptor S5.4 is concerned, while some students 
will be able to apply condensation and reformulation strategies during the interlingual transfer, others would probably find it easier to do so intralingually.

An example of how this type of activity has been implemented in PluriTAV's subtitling DS can be found in activity B4 within session 4, where students are asked to subtitle an audiovisual advertisement they have created in S/AL and translated into the L1.

\subsubsection{Sample activity 2. Segmentation of subtitles}

- Material needed: Clip and script or subtitles in L1 or S/AL

- Aims:

- Identify units of meaning

- Segment the text according to time and space restrictions, as well as to syntactic and semantic considerations

- Mediation skills and FREPA descriptors targeted: See Table 3 below

- Example of this type of sample activity within a PluriTAV DS:

http://citrans.uv.es/pluritav/sd/resources/sd/SD_SUBTITLING.pdf (Session 2, activities B3 and B4)

Table 3. Mediation skills and FREPA descriptors related to subtitle segmentation

\begin{tabular}{|l|l|}
\hline $\begin{array}{l}\text { Mediation skills } \\
\text { (Adapted from CEFR Companion Volume 2018, } \\
\text { 108-129) }\end{array}$ & FREPA descriptors \\
\hline $\begin{array}{l}\text { Modifying the structure of sentences to } \\
\text { improve legibility and comply with }\end{array}$ & $\begin{array}{l}\text { S6.1.1 Can reformulate (e.g. by } \\
\text { simplifying the structure of the utterance, } \\
\text { relevant spatio-temporal considerations in the vocabulary or by making }\end{array}$ \\
\hline
\end{tabular}




\begin{tabular}{|l|l|}
\hline subtitling (semantic and syntactic & S3.7.1 Can compare sentence structures in \\
considerations, and space restrictions) & different languages \\
\cline { 2 - 2 } & $\begin{array}{l}\text { S3.8 Can compare grammatical functions } \\
\text { of different languages }\end{array}$ \\
\hline
\end{tabular}

In this sample activity students are given a clip with some proposed subtitles in the L1 or S/AL. When necessary, they have to segment, or distribute, the text in two lines within a single subtitle, which should be semantically and syntactically self-contained (Díaz-Cintas and Remael 2007, 172). An ability to reformulate and reorganise information (descriptor S6.1.1) is needed to ensure that a specific number of characters is not exceeded, and that syntactic and semantic units are kept in the same line-e.g. to look for synonyms or change a phrase's structure so that it fits in a single line- - This process also requires reflecting on sentence structure and comparing grammar functioning in different languages, thus targeting descriptors such as S3.7.1 or S3.8.

In PluriTAV's subtitling DS, within session 2, students were asked to analyse the segmentation of some subtitles for an advertisement (activity B3). Afterwards, they were prompted to segment a previously translated text into subtitles considering the need to maintain legibility and keep syntactic units together (activity B4).

\subsection{Dubbing}

Dubbing is a type of audiovisual translation which consists of replacing the original track of an audiovisual text's source language dialogues with another track on which translated dialogues have been recorded in the target language (Chaume 2012, 1). Although not as popular as subtitling in language learning, dubbing has been gradually gaining scholars' attention over the past years. Duff's (1989) pioneering manual proposed dubbing activities for 
language learning, emphasising the importance of reflecting on the translation of cultural elements and taking into account synchronisation between the translated dialogue and the image. In recent years, research has focused on the use of dubbing for the development of language skills in S/AL such as pronunciation (Sánchez-Requena 2018), vocabulary, fluency and creativity (Danan 2010), as well as grammar or language use in general (Martínez Sierra 2014).

Synchrony constraints, and in particular lip synchrony, are a key aspect of professional dubbing (Chaume 2012), where the translation of the script is modified by the dialogue writer, or the adapter, who rewrites the dialogues to meet lip-sync requirements (i.e. to match the translation to the onscreen character's voices and movements) before the actual recording takes place. When carrying out these synchronisation tasks in the language classroom, FREPA descriptors related to different phonetic and phonological systems (K6.5) are activated. Dialogue writers must also adapt dialogues to make them sound natural. This task usually requires cultural adaptation and a vast knowledge of sociocultural and sociolinguistic features which are also represented by FREPA descriptors (i.e. K13.2 or S3).

\subsubsection{Sample activity 1. Translation of cultural references for dubbing purposes}

- Material needed: Audiovisual clip ideally containing dialogues with cultural references in

L1 or S/AL and script of the selected excerpt

- Aims:

- Identify cultural references

- Translate the text focusing on cultural references, taking into account a specific type of audience

- Reflect on pragmatic differences in oral communication

- Mediation skills and FREPA descriptors targeted: See Table 4 below 
- Example of this type of sample activity within a PluriTAV DS:

http://citrans.uv.es/pluritav/sd/resources/sd/SD_DUBBING.pdf (Session 1, activity B7)

Table 4. Mediation skills and FREPA descriptors related to the translation of cultural references for dubbing purposes

\begin{tabular}{|l|l|}
\hline $\begin{array}{l}\text { Mediation skills } \\
\text { (Adapted from CEFR Companion Volume 2018, } \\
\text { 108-129) }\end{array}$ & FREPA descriptors \\
\hline Translating a written text —in speech and & K3.2 Possesses knowledge about one's \\
in writing — capturing nuances & own communicative repertoire (e.g. \\
& languages and varieties, discursive genres, \\
& forms of communication, etc.) \\
\cline { 2 - 3 } & K6.6 Knows that there is no word for \\
& word equivalence from one language to \\
& another \\
\hline Facilitating pluricultural space dealing & K13.2 Knows that there may be \\
with sociocultural and sociolinguistic & resemblances and differences between \\
differences & cultures \\
\cline { 2 - 3 } & S3.9 Can compare communicative \\
& in the verbal or non-verbal ways in which \\
& feelings are expressed in different \\
\hline
\end{tabular}




\begin{tabular}{|l|l|}
\hline & $\begin{array}{l}\text { K6.10.2 Knows that some speech acts } \\
\text { (e.g. the rituals of greeting, formulae of } \\
\text { politeness, etc.) which may seem to be the } \\
\text { same, may not necessarily function in the } \\
\text { same way from one language to another }\end{array}$ \\
\cline { 2 - 3 } & $\begin{array}{l}\text { K6.10.3 Knows that the rules of } \\
\text { conversation [...] may vary from one } \\
\text { language to another }\end{array}$ \\
\hline
\end{tabular}

In this sample activity students are asked to translate a dialogue that they have to synchronise and record in a subsequent task. While translating a dialogue that foregrounds specific pragmatic differences between languages (e.g. addressing one's boss), in addition to acknowledging the usual lack of word to word equivalence between languages (K6.6), they will encounter challenges that may require reflecting on and resorting to their full communicative repertoire in the target language (be it the L1 or the S/AL) to capture and render all the nuances of the source text (K3.2). Audiovisual texts usually include cultural features referring not only to specific elements but also to sociopragmatic aspects. For this reason, they are a suitable tool to work on several descriptors that result in different cultural acknowledgments and comparisons between cultures (K13.2). When choosing the filmic excerpt to work on, it could be interesting to look for one featuring two or more characters in order to compare communicative cultures (S3.9), and to explore speech acts (K6.10.2) and rules of conversation (K6.10.3). Moreover, dialogues featuring different dramatic situations allow working on the expression of feelings (K6.10.1). It should also be noted that, although further adaptation will be needed later on, resorting to translation for dubbing activities in this case allows students to focus clearly on the rendering of differences between languages with 
no change of mode involved (oral utterances are also rendered orally). In doing so, they are exposed to audiovisual cues belonging to different cultures which are also similar to those experienced in real-life conversation, which constitutes yet another benefit of using dubbing for PPC acquisition.

All these features are present in activity B7 within session 1 of PluriTAV's dubbing DS, which focuses on the job interview as a textual genre. In this activity, students are asked to translate a scene where the main character attends precisely a job interview.

\subsubsection{Sample activity 2. Synchronisation of an audiovisual script for dubbing purposes}

- Material needed: Clip in L1 and script of the selected excerpt, which would have been translated in a previous task

- Aims:

- Reflect on the importance of meeting synchronisation requirements

- Find relevant alternatives to the words that do not coincide phonetically with onscreen actors' lip movements

- Reflect on the characteristics of S/AL's oral features and its differences and similarities with the L1

- Mediation skills and FREPA descriptors targeted: See Table 5 below

- Example of this type of sample activity within a PluriTAV DS:

http://citrans.uv.es/pluritav/sd/resources/sd/SD_DUBBING.pdf (Session 2, activity B2)

Table 5. Mediation skills and FREPA descriptors related to the synchronisation of an audiovisual script for dubbing purposes 


\begin{tabular}{|l|l|}
\hline $\begin{array}{l}\text { Mediation skills } \\
\text { (Adapted from CEFR Companion Volume 2018, } \\
\text { 108-129, 132-146) }\end{array}$ & FREPA descriptors \\
\hline $\begin{array}{l}\text { Comparing prosodic skills in more than } \\
\text { one language }\end{array}$ & K6.5.3 Knows that different languages \\
& may resemble each other or may vary in \\
& S3.2 Can perceive proximity and distance \\
& between sounds (or can discriminate \\
& aurally) \\
\hline Analysing verbal and non-verbal & K6.10 Knows that there are similarities \\
communication & and differences between verbal or non- \\
& verbal communication systems \\
\hline
\end{tabular}

In this sample activity, students are asked to synchronise a text that they have previously translated. Before recording a clip for dubbing purposes, it is customary to read out loud the dialogues while playing the video to verify that the translation makes sense and is synchronised with the characters' lips and bodies. When mimicking this professional practice, if dialogues are not synchronised, students have to decide what can be changed and modify their translation accordingly. When doing so, they will need to consider verbal and non-verbal communication elements (K6.10), as well as the phonetic and phonological systems of the languages involved, paying attention to elements such as rhythm, accentuation or intonation (K6.5.3). These adjustments will be more or less important depending on the distance and proximity between sounds in the languages involved (S3.2).

An example of a synchronisation activity can be found in activity B2 within session 2 of PluriTAV's dubbing DS, where students are asked to synchronise a text they have 
previously translated (session 1, activity B7). The text will then be recorded in activity $\mathrm{C} 1-$ within the same session-, completing the dubbing process.

\section{Final remarks}

The main aim of this article has been to illustrate the theoretical framework sustaining the PluriTAV project and to reflect on the potential of AVT for the acquisition of PPC. This has been done by discussing the three principles that have guided the conceptualisation of the PluriTAV project, which in turn have foregrounded essential connections between three main axes: specific translation subcompetences relevant in a TOLC context, which we have referred to as transfer/mediation skills; a selection of FREPA plurilingual/pluricultural descriptors; and AVT as a type of mediation activity, with a focus on dubbing and subtitling. The resulting theoretical framework draws on relevant literature on language teaching and learning (with a special focus on pluralistic approaches and multilingualism) and studies that highlight the usefulness of translation/AVT in language learning, as well as on current frameworks.

Far from being exhaustive, the aim of the PluriTAV framework is to serve as a useful tool for the implementation of pluralistic approaches to language teaching and learning through AVT tasks. It is our hope that not only researchers, but also language teachers will find this framework helpful, and that it will be complemented in the future. The aim of the sample activities provided in section 3 is precisely to illustrate how AVT tasks could be used in a wide range of contexts to work on plurilingual and pluricultural competence. While our experience in PluriTAV has revealed the advantages of implementing these activities in a multilingual context (cf. Martínez Sierra, forthcoming), with students resorting to their repertoires in English, Spanish and Catalan (but also in languages such as German or Italian), our approach can also be implemented in a monolingual context, where AVT is the driving 
force behind the acquisition of PPC. As has been discussed above, and as the DSs that the PluriTAV team has created reveal, these competences can be addressed through a wide range of activities that might not involve translation as such. Likewise, plurilingual and pluricultural competence is not at all exclusive to AVT. However, we believe that AVT, inasmuch as it subsumes a wide range of interlingual, intralingual and intersemiotic practices, is the ideal candidate to bring these competences to the language classroom, while increasing motivation and relying on students' independence when working both with their L1 and their S/AL. In the same way as audiovisual texts perfectly represent the multilingual and multicultural societies we live in, AVT adeptly captures the 'translation turn' we are witnessing, where AVT tasks can be used both as a means to improve PPC, and as an end in the acquisition of transfer/mediation skills which will be extremely useful to multilingual language learners. 


\section{Acknowledgements}

This research was conducted as part of the research project PluriTAV (ref. FFI2016-74853-P, 2017-2019), funded by the Agencia Estatal de Investigación (AEI) and the European Regional Development Fund (ERDF). 


\section{Notes}

1. From this point onwards, the term Second/Additional Language (S/AL) will be used to refer to the language that is being taught, and first language (L1) to refer to the students' main language of communication. Although the processes of acquiring a second language or additional languages bear important differences, they also have aspects in common (Cenoz 2008). In addition, we believe that AVT can be used in both second and additional language learning contexts to develop PPC in close interaction with the students' L1.

2. For instance, Cerezo-Merchán $(2018,471)$ refers to "the capacity of synthesis-i.e. familiarity with techniques to streamline texts_-", as a methodological and strategic competence which is essential in AVT in general and subtitling in particular. This subcompetence is very closely related to the summarising skills mentioned in both FREPA (i.e. descriptor K3.4) and the latest CEFR Companion Volume. 


\section{References}

Armand, Françoise, Érica Maraillet, Isabelle Anne Beck, Patricia Lamarre, Marielle Messier, and Sophie Paquin. 2004. "Pour éveiller à la diversité linguistique. Le projet Elodil." Québec Français 132: 54-57.

Caimi, Annamaria. 2006. "Audiovisual Translation and Language Learning: The Promotion of Intralingual Subtitles.” The Journal of Specialised Translation 6: 85-98.

Candelier, Michel, Antoinette Camilleri-Grima, Véronique Castellotti, Jean-François de Pietro, Ildikó Lörincz, Franz-Joseph Meissner, Anna Schröder-Sura, and Artur Noguerol. 2012. Framework of Reference for Pluralistic Approaches to Languages and Cultures. Edited by Council of Europe. Graz: European Centre for Modern Languages.

Carreres, Ángeles. 2014. "Translation as a Means and as an End: Reassessing the Divide.” The Interpreter and Translator Trainer 8 (1): 123-135.

Carreres, Ángeles, María Noriega-Sánchez, and Carme Calduch. 2018. Mundos en palabras. Learning Advanced Spanish through Translation. London: Routledge.

Celic, Christina, and Kate Seltzer. 2012. "Translanguaging: A CUNY-NYSIEB Guide for Educators.” New York: CUNY-NYSIEB.

Cenoz, Jasone. 2008. "The Acquisition of Pragmatic Competence and Multilingualism in Foreign Language Contexts.” In Intercultural Language Use and Language Learning, ed. by Eva Alcón Soler and M. Pilar Safont Jordà, 123-140. Dordrecht: Springer. Cenoz, Jasone, and Durk Gorter. 2014. "Focus on Multilingualism as an Approach in Educational Contexts." In Heteroglossia as Practice and Pedagogy, ed. by Adrian Blackledge and Angela Creese, 239-254. Dordrecht: Springer.

Cerezo-Merchán, Beatriz. 2018. “Audiovisual Translator Training.” In The Routledge Handbook of Audiovisual Translation, ed. by Luis Pérez-González, 468-482. London: Routledge. 
Chaume, Frederic. 2012. Audiovisual Translation: Dubbing. Manchester: St. Jerome.

Coste, Daniel, Danièle Moore, and Geneviève Zarate. (1997) 2009. “Competence plurilingue et pluriculturelle.” Strasbourg: Council of Europe.

Council of Europe. 2001. Common European Framework of Reference for Languages:

Learning, Teaching, Assessment. Strasbourg: Council of Europe.

Council of Europe. 2018. Common European Framework of Reference for Languages:

Learning, Teaching, Assessment. Companion Volume with New Descriptors. Strasbourg:

Council of Europe.

Cummins, James. 1979. "Linguistic Interdependence and the Educational Development of Bilingual Children.” Review of Educational Research 49 (2): 222-251.

Cummins, James. 2007. “Rethinking Monolingual Instructional Strategies in Multilingual Classrooms." Canadian Journal of Applied Linguistics 10 (2): 221-240.

Danan, Martine. 1992. "Reverse Subtitling and Dual Coding Theory: New Directions for Foreign Language Instructions.” Language Learning 42 (4): 67-77.

Danan, Martine. 2010. “Dubbing Projects for the Language Learner: A Framework for Integrating Audiovisual Translation into Task-Based Instruction." Computer Assisted Language Learning 23 (5): 441-456.

De Pietro, Jean-François. 2014. “Des approches plurielles, oui mais combien?” In Didactique du plurilinguisme. Approches plurielles des langues et des cultures. Autour de Michel Candelier, ed. by Christel Troncy, 227-240. Rennes: Presses universitaires de Rennes. Díaz-Cintas, Jorge. 1995. “El subtitulado como técnica docente.” Vida Hispánica 12: 10-14.

Díaz-Cintas, Jorge, and Aline Remael. 2007. Audiovisual Translation: Subtitling. Manchester: St Jerome.

Dolz-Mestre, Joaquim, and Bernard Schneuwly. 1998. Pour un enseignement de l'oral: Initiation aux genres formels à l'école. Paris: ESF. 
Duff, A. 1989. Translation. Oxford: Oxford University Press.

Fons Esteve, Montserrat. 1999. Llegir i escriure per viure. Alfabetització inicial i ús real de la llengua escrita a l'aula. Barcelona: La Galera.

García, Ofelia, and Kate Seltzer. 2016. "The Translanguaging Current in Language

Education.” In Flerspråkighet som resurs [Multilingualism as a Resource], ed. by Björn Kindenberg, 19-30. Stockholm: Liber.

González-Davies, Maria. 2004. Multiple Voices in the Translation Classroom. Amsterdam: John Benjamins.

González-Davies, Maria. 2014. “Towards a Plurilingual Development Paradigm: From Spontaneous to Informed Use of Translation in Additional Language Learning." The Interpreter and Translator Trainer 8 (1): 8-31.

González-Davies, Maria. 2017. “The Use of Translation in an Integrated Plurilingual Approach to Language Learning: Teacher Strategies and Best Practices.” Journal of Spanish Language Teaching 4 (2): 124-135.

González-Davies, Maria. 2020. "Developing Mediation Competence through Translation.” In The Routledge Handbook of Translation and Education, ed. by Sara Laviosa and Maria González-Davies, 434-450. London: Routledge.

Guasch, Oriol. 2007. "La educación multilingüe: un reto para el profesorado.” Cultura y Educación 19 (2): 135-147.

Herdina, Phillip, and Ulrike Jessner. 2002. A Dynamic Model of Multilingualism: Perspectives of Change in Psycholinguistics. Clevedon: Multilingual Matters. Hufeisen, Brita, and Gerhard Neuner, eds. 2004. The Plurilingualism Project: Tertiary Language Learning: German after English. Strasbourg: Council of Europe. Incalcaterra McLoughlin, Laura, Jennifer Lertola, and Noa Talaván. 2018. "Editorial: Audiovisual Translation in Applied Linguistics: Educational Perspectives." Translation 
and Translanguaging in Multilingual Contexts 4 (1): 1-8.

Jakobson, Roman. 1959. “On Linguistic Aspects of Translation.” In On Translation, ed. by Arthur Reuben, 232-239. Harvard Studies in Comparative Literature. Cambridge, MA: Harvard University Press.

Kelly, Dorothy. 2005. A Handbook for Translator Trainers: A Guide to Reflective Practice. Manchester: St Jerome.

Lertola, Jennifer. 2012. "The Effect of the Subtitling Task on Vocabulary Learning." Translation Research Projects 4: 61-70.

Lertola, Jennifer. 2019. Audiovisual Translation in the Foreign Language Classroom: Applications in the Teaching of English and Other Foreign Languages. Researchpublishing.net.

Martínez Sierra, Juan José. 2014. "The Use of Audiovisual Translation Software in Second Language Teaching." Journal of Foreign Language Teaching and Translation Studies 3 (1): 74-85

Martínez Sierra, Juan José, ed. Forthcoming. Multilingualism, Translation and Language Teaching. València: Tirant Lo Blanch.

Nussbaum, Luci. 2014. "Una didàctica del plurilingüisme.” Bellaterra Journal of Teaching \& Learning Language \& Literature 7 (3): 1-13.

PACTE group. 2017. “Conclusions: Defining Features of Translation Competence.” In Researching Translation Competence by PACTE Group, ed. by Amparo Hurtado Albir, 281-302. Amsterdam: John Benjamins.

Pinho, Ana Sofia, and Ana Isabel Andrade. 2009. "Plurilingual Awareness and Intercomprehension in the Professional Knowledge and Identity Development of Language Student Teachers." International Journal of Multilingualism 6 (3): 313-329. Pintado Gutiérrez, Lucía. 2019. "Mapping Translation in Foreign Language Teaching: 
Demystifying the Construct." In Translation and Language Teaching: Continuing the

Dialogue, ed. by Nicolas Frœliger and Melita Koletnik, 23-38. Cambridge: Cambridge Scholars Publishing.

Sánchez-Requena, Alicia. 2018. "Intralingual Dubbing as a Tool for Developing Speaking Skills." Special Issue of Translation and Translanguaging in Multilingual Contexts.

Audiovisual Translation in Applied Linguistics: Beyond Case Studies 4 (1): 102-128.

Talaván, Noa. 2006. “Using Subtitles to Enhance Foreign Language Education.” Porta

Linguarum 6: 41-52.

Talaván, Noa. 2010. "Subtitling as a Task and Subtitles as Support: Pedagogical

Applications." In New Insights into Audiovisual Translation and Media Accessibility, ed.

by Jorge Díaz-Cintas, Anna Matamala, and Josélia Neves, 285-299. Amsterdam: Rodopi.

Talaván, Noa, Ana Ibáñez, and Elena Bárcena. 2017. "Exploring Collaborative Reverse

Subtiling for the Enhancement of Written Production Activities in English as a Second

Language." ReCALL 29 (1): 39-58.

Vanderplank, Robert. 1988. “The Value of Teletext Sub-Titles in Language Learning.” ELT

Journal 4 (4): 272-281.

Williams, Helen, and David Thorne. 2000. "The Value of Teletext Subtitling as a Medium for Language Learning.” System 28 (2): 217-228.

\section{Address for correspondence}

Rocío Baños

Centre for Translation Studies

University College London

Gower Street

London, WC1E 6BT

United Kingdom

r.banos@ucl.ac.uk

\section{Co-authors information}


Anna Marzà

Departament de Pedagogia, Didàctica de les Ciències Socials, la Llengua i la Literatura Facultat de Ciències Humanes i Socials

Universitat Jaume I

Av. Sos Baynat $\mathrm{s} / \mathrm{n}$

12071 Castelló

Spain

amarza@uji.es

Gloria Torralba

Departament de Pedagogia, Didàctica de les Ciències Socials, la Llengua i la Literatura Facultat de Ciències Humanes i Socials

Universitat Jaume I

Av. Sos Baynat s/n

12071 Castelló

Spain

gtorralb@uji.es 